\title{
Common Diabetogenic Agents Used in Experimental Animals: A Review
}

\author{
Isam M Abu Zeid ${ }^{1,2}$
}

${ }^{1}$ Department of Biological Sciences, Faculty of Sciences, King Abdulaziz University, Saudi Arabia

${ }^{2}$ Princess Dr Najla Bint Saud Al-Saud Center for Excellence Research in Biotechnology, King Abdulaziz University, Jeddah, Saudi Arabia

Correspondence Author: Isam M Abu Zeid, Department of Biological Sciences, Faculty of Sciences, King Abdulaziz University, Saudi Arabia Email: abuzeidmm@yahoo.com

Received date: 12 May 2019, Accepted date: 24 September 2019, Online date: 5 October 2019

Copyright: (C) 2019 Isam M Abu Zeid. This is an open-access article distributed under the terms of the Creative Commons Attribution License, which permits unrestricted use, distribution, and reproduction in any medium, provided the original author and source are credited.

\begin{abstract}
Diabetes mellitus is a complex metabolic disorder marked by a chronic hyperglycaemic status generated because of insulin secretion deficiency; resistance to insulin effect or both. Screening models are essential in offering insights without invasive processes in humans. Disease introduction on a target cell model needs a clear investigation so that complication of treatment can be established. The induction of diabetes mellitus aims to use animals under replica insulin deficiency or insensitivity similar to human physiology. This review provides useful information on the common synthetic chemicals that emerge as diabetogenic agents.
\end{abstract}

Keywords: Diabetes, Diabetogenic agents, Animals, Streptozotocin, Alloxan

\section{INTRODUCTION}

Diabetes mellitus is a complex metabolic disorder marked by a chronic hyperglycemic status generated because of insulin secretion deficiency; resistance to insulin effect or both [1-3]. The etiology of diabetes mellitus comprises the causes, symptoms and physiological changes that attend on the onset of the disease. Genes, hypertension obesity, environment, age, psychological stress, and diet are all contributory causes [4-6].

The introduction of diabetes mellitus studies using an animal was done in the 1980s when a dog underwent surgical pancreatectomy [7]. Various developments from gene transplants to in-vitro experiments on mice have emerged [7]. The induction of diabetes mellitus aims to use animals under replica insulin deficiency or insensitivity similar to human physiology [8]. Dietary and experimental models were used to monitor gradual resistance against insulin for noninsulin dependent diabetes mellitus (NIDDM) replicas [8]. Certain experimental animals have strong insulin-secretion physiologies while others have naturally weak beta cells. Models underwent various dosage of classifications to investigate parallel tendencies in human diabetes mellitus [8].

Two major methods have proved diabetes mellitus induction, namely alloxan-and-STZ induction [7]. Both methods simulate diabetes mellitus through pharmacological damage of the beta cells. The method inhibits insulin secretion because both chemicals have similar structures as serum sugar, making them receptive to beta cells and the follow-up damage [7].

\section{Induction of Diabetes Mellitus by Streptozotocin (STZ)}

Streptozotocin (STZ) (2-deoxy-2-\{[methyl (nitroso) amino] carbonyl $\}$ amino)- $\beta$-D-glucopyranose) is a naturally occurring diabetogenic compound, produced by the soil bacterium Streptomyces achromogenes [9, 10]. STZ was named by USA agency [11]. Since 1960, STZ is the most widely used chemical compound for the development of a laboratory model of diabetes which simulates humans' diabetes [12]. STZ induces diabetes in rats, mice, monkeys, hamsters, rabbits and guinea pigs [10,13]. Researchers can make observations with the gradual development of induced diabetes [14]. STZ works in rats through gradual inflammation of pancreatic tissue followed eventually by the death of beta cells [11]. Streptozotocin is used in the induction of diabetes mellitus due to its ease of access [14].

Streptozotocin is glucose linked to methyl nitrosourea moiety (Figure 1). The glucose is responsible for STZ passage and accumulation inside the pancreatic beta cells via a glucose 2 transporter (GLUT2) while the methyl nitrosourea moiety is responsible for its cytotoxicity [15]. All living cells that express GLUT2 including pancreatic beta cells, hepatocytes, and renal tubular cells are very susceptible to STZ-induced toxicity [16]. This clarifies the cause of liver and kidney damage in STZ injected animals. Moreover, the clinical effect of STZ on any cell inhibits deoxyribonucleic acid (DNA) metabolism in warm-blooded animals and eventually incurs cell demise [9]. Its similarity with blood sugar makes it access beta cells where it has an annihilative effect after it bonds selectively onto glucose transporter type 2 (GLUT2) [13].

Streptozotocin induction on rats requires a gradual period to completely cause the metabolic disorder in the rat [9]. The first dosage constitutes an antihyperglycemic defensive mechanism from the beta cells of the rat to compensate for the sudden increment in glucose levels, followed by the gradual stoppage of reactant hypoglycemia [9]. The use of STZ has effects on masculine rats than their female counterparts. The disparity in gender sensitiveness to the chemical could be extreme [13]. Hyperglycemia can range from $200 \mathrm{mg} / \mathrm{dL}$ in the male group with little or no response in female mice upon equal dose STZ induction [13]. The gap may be due to potency of the female reproductive hormone which buffers beta cells [13]. Streptozotocin is an accessible, potent and standardized chemical that can work on diverse species of rodents to help test drugs and ethnomedicine such as plant extracts on diabetes mellitus models [13].

There are three stages of changes in blood glucose level after STZ injection. The first stage occurs two hours after STZ injection and is characterized by a transient increase in blood glucose caused by liver glycogen breakdown, followed by hypoglycaemia occurring within 6 hours after STZ injection and may end with animal death. The last stage occurred 48 hours after the injection of STZ and characterized by structural alterations in pancreatic beta cells [10, 17]. In another study, the third stage occurs after 3 days of injecting STZ and reaching its peak within 2-4 weeks leaving behind a small percentage of functioning beta cells of the pancreas leading to diabetes symptoms [10] 
In the research that investigates the effectiveness of some medicinal plants for the treatment of diabetes using the STZ model, the plant is preferred to be given after 11 days of STZ injection until the period during which the animal can recover from high sugar after rising in the first stage [10]. STZ should be injected into animals after feeding and avoid being fasted to avoid a severe drop in blood sugar and reduce mortality [18]. The STZ solution should be stored in the refrigerator and can be kept at room temperature, but it must be protected from light and used within 12 hours after the preparation. Because of the proposed STZ solution instability, it is recommended that it must be injected within 10 minutes after reconstitution [10].

Type-1 DM, as well as type-2 DM, can be produced using STZ either alone or in combination with other chemicals or with particular dietary regimen [19]. Ventura-Sobrevilla et al. [15] reported that type-1 DM can be developed in mice by injecting one high dose (130 or $150 \mathrm{mg} / \mathrm{kg}$ ) of STZ or using multiple doses (40 $\mathrm{mg} / \mathrm{kg}$ ). However, type-2 DM can be developed using different designs, including, STZ injection after nicotinamide administration [20]. injection of STZ in a dose of $35 \mathrm{mg} / \mathrm{kg}$ after high-fat diets [21]. or injections of STZ for new-born animals [22].

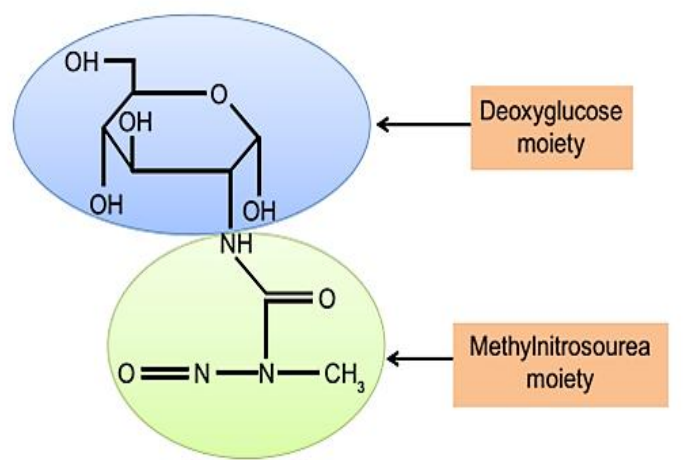

Figure 1. Chemical structure of streptozotocin [23].

\section{Induction of Diabetes Mellitus by Alloxan}

The chemical name of alloxan is 2,4,5,6 tetraoxypyrimidine; 2, 4, 5, 6- pyrimidinetetrone, which is present as alloxan hydrate (Figure 2) [24]. It is a wellknown diabetogenic agent widely used to induce diabetes mellitus in animals such as rabbits, rats, mice and dogs with different grades of disease severity by varying it dose [25]. Alloxan may cause type-1 DM by causing increased free radicals that cause the death of pancreatic beta cells [12]. It is useful for the induction of diabetes mellitus as it is similar to STZ [7]. Alloxan brings results similar to those of the human morbidity. It also induces liver damage similar to diabetes mellitus [26]. It shows varying and non-uniform results from improper standardization [27]. It exhibits $25 \%$ fatal outcome at $150 \mathrm{mg} / \mathrm{kg}$ dosage on mice [27].

There are four stages of changes in blood glucose level after alloxan injection. The first stage occurs within the first minutes after alloxan injection, lasts within 30 minutes and is characterized by a transient hypoglycemia caused by transient stimulation of insulin secretion. The second stage occurs one hour after administration of alloxan, lasts within 2-4 hours and is characterized by hyperglycaemia and decrease in insulin level caused by beta cells toxicity. The third stage occurs 4-8 hours after administration of alloxan, lasts for several hours and is caused by beta-cell membrane rupture resulting in severe hypoglycaemia. The fourth stage is the final permanent diabetic hyperglycaemic phase occurs $24-48$ hours after administration of alloxan and is caused by complete degranulation and loss of the integrity of the beta cells $[12,28]$.

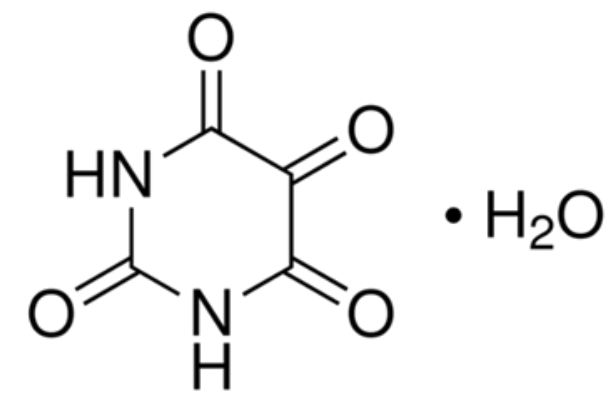

Figure 2. Chemical structure of alloxan [12].

\section{Other Diabetogenic Compounds}

Cyproheptadine is one of the diabetogenic compounds that stimulates appetite [29]. Therefore, it is recommended to people suffering from morbid thinness or anorexia. However, in people with normal weight, it leads to weight gains and diabetes mellitus [29]. Findings indicate that its long-term clinical application on tumors can lead to diabetes mellitus and overweight diseases, among other complications [30].

Anti-insulin serum is another natural compounds for the induction of mice and model animals with diabetes mellitus [31]. The evidence is that the serum in antibody form bonds with insulin resulting into limited access for metabolism occurring in the body. The event results to increase the glucose levels [31]. A related method involves the use of dithizone, a sulfurous chemical that boosts the levels of metals in lipoproteins including zinc, which increases diabetes mellitus incidence [31].

One of the roles of the growth hormone $(\mathrm{GH})$ is to protect the pancreatic tissue during the secretion of insulin thus overcoming the onset of insulin-dependent diabetes mellitus (IDDM) [32]. However, medical findings indicate that it contains a hyper-productive effect on pancreatic secretions, which triggers insulin insensitivity [33]. Repeated use of growth hormones in cats and dogs causes diabetes accompanied by urine acetone and ketonemia. Previous studies have suggested that long-term use of growth hormone causes a permanent state of hyperglycaemia and destruction of pancreatic beta cells with insulin scarcity [24].

One of the gene-dependent methods of induction of mice metabolic diseases is the 'chronic growth hormone [34]. Its caustic role in insulin insensitivity in non-insulin dependent diabetes mellitus is still unclear [34]. Its mechanism, however, dictates the control of an inhibitory gene that affects the stimulation of insulin release during a rise in blood sugar [34]. Accordingly, Gao et al. [34] tested a particular gene known as phosphatase and tensin homolog (PTEN) and found that the removal of the gene in the induction process led to better insulin insensitivity while its retention substantially boosted insulin insensitivity. These findings implied that the isolation of the gene might help to assess future approaches to diabetes mellitus control. Induction also targets the inadequacy of growth hormone, which makes cells unable to produce enough insulin especially in old people undergoing growth hormone bypass operation [35]. Another method is induction under the presence of PTEN genes [34].

Gold thioglucose is diabetogenic compound induced type-2 DM associated with polyphagia and obesity [24]. Monosodium glutamate induces type-2 DM without hyperphagia [24]. Dithizone produced diabetes symptoms in cats, rabbits, golden hamsters and mice [24]. Ferric nitrilotriacetate produces diabetes symptoms such as hyperglycaemia, glycosuria, ketonemia, and ketonuria in rats and rabbits injected with a large daily dose after nearly 60 days [9]. Corticosteroid 
Citation: Isam M Abu Zeid, 2019. Common Diabetogenic Agents Used In Experimental Animals: A Review. Journal of Applied Sciences Research., 15(5): 2427. DOI: $10.22587 /$ jasr.2019.15.5.5

can induce diabetes, especially prednisolone and dexamethasone. It resists insulin action and stimulates hepatic gluconeogenesis, resulting in an increase in hepatic glucose formation, insulin resistance and hyperglycaemia [36].

\section{REFERENCES}

[1] Aljaghthmi, O. H., H.M. Heba and I.M.Abu Zeid, 2017. Antihyperglycemic properties of mangrove plants (Rhizophora mucronata and Avicennia marina): An Overview. Advances in Biological Research, 11(4):61-170.

[2] Heindel, J.J., B. Blumberg, M. Cave, R. Machtinger, A. Mantovani, M. A. Mendez, A. Nadal, P. Palanza, G. Panzica, R. Sargis, L. N. Vandenberg and F. Vom Saal, 2017. Metabolism disrupting chemicals and metabolic disorders. Reproductive Toxicology, 8: 3-33.

[3] Al-Thobaiti, S.A. and I.M. Abu Zeid, 2019. Antidiabetic potential of Balanites aegyptiaca kernel, flesh and their combination against streptozotocin-induced hyperglycemia in male Wister rats. Tropical Journal of Pharmaceutical Research, 18(2): 263-271.

[4] Murad, M.A., S.S. Abdulmageed, R. Iftikhar and B.K. Sagga, 2014. Assessment of the common risk factors associated with type 2 diabetes mellitus in Jeddah". International Journal of Endocrinology, 2014(2014):1-9.

[5] Marinho, N.B., H.C.A. Vasconcelos, A.M.P.C. Alencar, P.C. Almeida and M.M.C. Damasceno, 2013. Risk for type 2 diabetes mellitus and associated factors. Acta Paulista de Enfermagem, 26:569-574.

[6] Stanifer, J.W., C.R. Cleland, G.J. Makuka, J.R. Egger, V. Maro, H. Maro, F. Karia, U.D. Patel, M.J Burton and H. Philippin, 2016. Prevalence, risk factors, and complications of diabetes in the kilimanjaro region: A population-based study from Tanzania. Plos One, 11: 1-13.

[7] Radenkovic, M., M. Stojanovic and M. Prostran, 2016. Experimental diabetes induced by alloxan and streptozotocin: the current state of the art. Journal of Pharmacological and Toxicological Methods, 78: 13-31.

[8] Srinivasan, K. and P. Ramarao, 2007. Animal models in type 2 diabetes research: An overview. Indian Journal of Medical Research, 125(3): 451-472.

[9] Etuk, E.U, 2010. Animal models for studying diabetes mellitus. Agriculture and Biology Journal of North America, 1(2): 130-134.

[10] Eleazu, C.O., K.C. Eleazu, S. Chukwuma and U.N. Essien, 2013. Review of the mechanism of cell death resulting from streptozotocin challenge in experimental animals, its practical use and potential risk to humans. Journal of Diabetes and Metabolic Disorders, 12(60): 1-7.

[11] Singh, M. P. and K. Pathak, 2015, Animal models for biological screening of anti-diabetic drugs: An overview. European Journal of Experimental Biology, 5(5):37-48.

[12] Lenzen, S. 2008. The mechanisms of alloxan- and streptozotocin-induced diabetes. Diabetologia, 51(2): 216-226.

[13] Deeds, M.C., J.M. Anderson, A.S. Armstrong, D.A. Gastineau, H.J. Hiddinga, A. Jahangir, N.L. Eberhardt and Y.C. Kudva, 2011. Single dose streptozotocin-induced diabetes: Considerations for study design in islet transplantation models. Lab. Animal, 45(3):131-140.

[14] Islam, S.M. and T. Loots du, 2009. Experimental rodent models of type 2 diabetes: A review. Methods and Findings in Experimental and Clinical Pharmacology, 31(4): 249-261.

[15] Ventura-Sobrevilla, J., V.D. Boone-Villa, C.N. Aguilar, R. Román-Ramos, E. Vega-Ávila, E. Campos-Sepúlveda and F. Alarcón-Aguilar, 2011. Effect of varying dose and administration of streptozotocin on blood sugar in male CD1 mice. Proceedings of the Western Pharmacology Society, 54:5-9.

[16] Elsner, M., B. Guldbakke, M. Tiedge, R. Munday and S. Lenzen, 2007. Relative importance of transport and alkylation for pancreatic beta cell toxicity of streptozotocin. Diabetolgia, 2007(2007):1528-1533.

[17] Joo, H.L., H.Y. Si, M.O.H. Jung and G.L. Myung, 2010. Pharmacokinetics of drugs in rats with diabetes mellitus induced by alloxan or streptozocin: Comparison with those in patients with type I diabetes mellitus. Journal of Pharmacy and Pharmacology, 62:1-23.

[18] Arindkar, S., M.J. Mahesh Kumar, R.C. Juyal, S.S. Majumdar, and N. Perumal, 2012. The effect of fasting on haematology serum biochemistry parameters on STZ induced CD1 mice and diabetic db/db mice. Journal of Drug Metabolism and Toxicology, 3:137, 1-4.

[19] Ghasemi, A., S. Khalifi and S. Jedi, 2014. Streptozotocin-nicotinamide-induced rat model of type 2 diabetes. Review. Acta Physiologica Hungarica, 101(4):408-420.

[20] Szkudelski, T., 2012. Streptozotocin-nicotinamide-induced diabetes in the rat. Characteristics of the experimental model. Experimental Biology and Medicine (Maywood), 237(5):481-490.

[21] Skovso, S., 2014. Modeling type 2 diabetes in rats using high fat diet and streptozotocin. Journal of Diabetes Investigation, 5(4):349-358.

[22] Patil, M.A., P. Suryanarayana, U.K. Putcha, M. Srinivas and G.B. Reddy, 2014. Evaluation of neonatal streptozotocin-induced diabetic rat model for the development of cataract. Oxidative Medicine and Cellular Longevity, 2014(2014): 1-10.

[23] Wu, J. and L.J. Yan, 2015. Streptozotocin-induced type 1 diabetes in rodents as a model for studying mitochondrial mechanisms of diabetic $\beta$-cell glucotoxicity. Diabetes, Metabolic Syndrome and Obesity, 8:181-188

[24] Tripathi, V. and J. Verma, 2014. Different models used to induce diabetes: A comprehensive review. International Journal of Pharmacy and Pharmaceutical Sciences, 6(6):29-32.

[25] Iranloye, B.O., A.P. Arikawe, G. Rotimi and A.O. Sogbade, 2011. Anti-diabetic and anti-oxidant effects of Zingiber officinale on alloxan-induced and insulin-resistant diabetic male rats. Nigerian journal of physiological sciences, 26(1):89-96.

[26] Lucchesi, A.N., L.L. Cassettari and C.T. Spadella, 2015. Alloxan-induced diabetes causes morphological and ultrastructural changes in rat liver that resemble the natural history if chronic fatty liver disease in humans. Journal of Diabetes Research, 2015(2015):1-11.

[27] Misra, M. and U. Aiman, U. 2012. Alloxan: an unpredictable drug for diabetes induction? Indian Journal of Pharmacology, 44(4): 538-539.

[28] Rohilla, A. and S. Ali, 2012. Alloxan induced diabetes: Mechanisms and effects. International Journal of Research in Pharmaceutical and Biomedical Sciences, 3 (2):819-823.

[29] Kazemi, S.A., M.K. Yekta, R. Fallah, D.N. Diaz and K. Eftekhari, 2017. Evaluation of cyproheptadine hydrochloride effects on weight gain in underweight children with anorexia: A randomized clinical trial. International Journal of Pediatrics, 5: 6413-6419.

[30] Lulebo, A.M., C.D. Bavuidibo, E.M. Mafuta, J.D. Ndelo, L.C.M. Mputu, D.M. Kabundji and P.B. Mutombo, 2016. The misuse of cyprohetadine: A noncommunicable disease risk behavior in Kinshasa population, democratic republic of Congo. Substance Abuse Treatment, Prevention, and Policy, 11:1-7.

[31] Karthikeyan, M., T. Balasubramanian and P. Kumar, 2016. In-vivo animal models and in-vitro techniques for screening antidiabetic activity. Journal of Developing Drugs, 5: 1-6.

[32] Schmidt, D.K., R. Villares, L. Gomez, C. Martinez and M. Mellado, 2013. Growth hormone effect on type 1 diabetes development (P4546). Journal of Immunology, 190:197-198.

[33] Wang, D., N. Zhao and Z. Zhu, 2015. Recombinant human growth hormone in the treatment of diabetes: Report of three cases and review of the relative literature. International Journal of Clinical and Experimental Medicine, 8:8243-8248.

[34] Gao, Y., P. Su, C. Wang, K. Zhu, X. Chen, S. Liu and J. He, 2013. The role of PTEN in chronic growth hormone-induced hepatic insulin resistance. Plos One, 8: 1-10. 
[35] Luger, A., A.F. Mattson, M. Kollowska-Haggstrom, M. Thunander, M. Goth, J. Verhelst and R. Abs, 2012. Incidence of diabetes mellitus and evolution of glucose parameters in growth hormone-deficient subjects during growth hormone replacement therapy: A long-term observational study. Diabetes Care, 35:57-62.

[36] Heather, A., C. Ferris and R. Kahn, 2012. New mechanisms of glucocorticoids-induced insulin resistance: Make no bones about it. Journal of Clinical Investigation, 2012(2012):3854-3857. 